\title{
ANTI-PERIODIC BOUNDARY VALUE PROBLEMS FOR NONLINEAR HIGHER ORDER FUNCTIONAL DIFFERENCE EQUATIONS
}

\author{
YUJI LIU
}

\begin{abstract}
Sufficient conditions for the existence of at least one solution of anti-periodic boundary value problems for nonlinear functional difference equations are established. We allow $f$ to be at most linear, superlinear or sublinear in obtained results.
\end{abstract} equation.

Mathematics subject classification (2000): 34B10, 34B15.

Key words and phrases: Solutions, anti-periodic boundary value problem, functional difference

\section{REFERENCES}

[1] K. DeImling, Nonlinear Functional Analysis, Springer-Verlag, New York, 1985.

[2] Z. ZENG, Existence of positive periodic solutions for a class of nonautonomous difference equations, Electronic Journal of differential equations, 2006(2006:3)1-18.

[3] R. Zhang, Z. WAng, Y. Chen, J. Wu, Periodic solutions of a single species discrete population model with periodic harvest/stock, Comput. and Math. with Appl., 2000(39)77-90.

[4] M. MA, J. YU, Existence of multiple positive periodic solutions for nonlinear functional difference equations, J. Math. Anal. Appl.,2005(305)483-490.

[5] J. Sun, Positive solutions for first order discrete periodic boundary value problems, Applied Mathematics Letters, doi:10.1016/j.aml.2006.01.007, to appear.

[6] Y. WANG, Y. SHI, Eigenvalues of second-order difference equations with periodic and antiperiodic boundary conditions, Journal of Mathematical Analysis and Applications, 2005(309)56-69. 